\title{
Lobbying Inside (and) Out: Interest Group Behavior on Social Media
}

\author{
Kirsten Widner* \\ Maggie Macdonald ${ }^{\dagger}$ \\ Anna Gunderson $\ddagger$
}

September 21, 2020

\begin{abstract}
Studies of lobbying often draw distinctions between inside lobbying - direct attempts to influence policy through meetings, campaign contributions, and other activities that build and leverage relationships with policymakers - and outside lobbying - activities such as protests, demonstrations, and media strategies that put indirect pressure on policymakers. These studies have found that while all groups increasingly use all available tactics, business and trade associations favor inside lobbying, and citizens' advocacy groups are more likely to engage in outside lobbying. This project reexamines this literature in the context of the recent growth in the use of social media and ask whether existing patterns of lobbying are replicated in the digital environment. We theorize that business and professional groups will be less likely to engage in social media use and, when they do use it, will be more likely to use social media platforms to build and reinforce relationships with policymakers. In contrast, we expect that citizens' advocacy groups will be most likely to engage in an online form of outside lobbying, using social media to inform the public and build grassroots support for their policy agendas. We test these expectations using an original dataset of Twitter and Facebook posts from interest groups. We find that outside lobbying messages are more frequent than inside lobbying messages on social media across all types of groups. Citizens' groups are significantly more likely to engage in social media use overall, and they are more likely to use it for both inside and outside lobbying messages than all other types of groups.
\end{abstract}

${ }^{*}$ Department of Political Science, University of Tennessee, Knoxville, TN, USA

${ }^{\dagger}$ Center for Social Media and Politics, New York University, New York, NY, USA

${ }^{\ddagger}$ Department of Political Science, Louisiana State University, Baton Rouge, LA, USA 
These networks suggest that digital activism has entered a second act, in which the tools of the Internet have been increasingly integrated into the hard-won structure of older movements.

Jane Hu, The New Yorker (August 3, 2020)

Interest groups play an important role in policymaking. They aggregate group interests and preferences for policymakers, and they provide information and ways to take action for members of the public (Grossmann 2012, Kollman 1998). The emergence and increasing prominence of social media over the last twenty years has the potential to reduce the costs of these activities by allowing organizations to share their messages directly with policymakers and the public at very little cost (Figenschou and Fredheim 2020). However, little is known about exactly whether and how interest groups use social media to advocate for policy change.

The literature on interest group advocacy has generally divided organizations' activities into two main categories: inside lobbying and outside lobbying. Inside lobbying activities are those that focus on building relationships with policymakers and communicating directly with those policymakers to persuade them support issues (Walker 1991). Outside lobbying activities are efforts to indirectly influence policymakers by informing and mobilizing members of the public (Kollman 1998). While most interest groups engage in a mix of inside and outside lobbying activities, scholars have found that business and professional groups focus more of their efforts on inside lobbying, while citizens' groups are more likely to engage in outside lobbying activities (Grossmann 2012, Kollman 1998, Walker 1991).

Many traditional lobbying activities require substantial resources. Inside lobbying, for example, may involve sending lobbyists to the capital, making campaign contributions, or throwing big events that allow interaction with multiple policymakers and supporters. Social media, on the other hand, presents a low-cost way to engage in direct, personalized communication with policymakers, the public, and other audiences (Gainous and Wagner 2014, Golbeck, Grimes and Rogers 2010, Johnson 2011). Posts are easy to make and free to disseminate. Interest groups could use this communication channel for either inside or outside lobbying activities. Social media could facili- 
tate inside lobbying by decreasing the barriers to access often involved in communicating directly with policymakers. It could facilitate outside lobbying by allowing organizations to communicate with members and voters and encourage grassroots activity. Do organizations use social media in these ways? And if they do, do they use a different mix of inside and outside strategies online than they have used in other settings? Or do they replicate the same patterns online that we have traditionally seen different types of groups follow?

This paper investigates these questions. It begins by reviewing the literature on inside and outside lobbying and the literature on social media use by interests groups to frame expectations. It hypothesizes that citizens' advocacy groups are most likely to engage in an online form of outside lobbying, using social media to inform the public and build grassroots support for their policy agendas. In contrast, it expects that business and professional groups are less likely to engage in social media use for any reason and, when they do use it, are more likely to use social media platforms to build and reinforce relationships with policymakers. The paper then describes an original dataset of Tweets and Facebook posts by interest groups and a provides an overview of general trends that appear in the data. Next, it uses the data to test expectations. It finds that outside lobbying predominates on social media for all types of interest groups. Citizens' groups are significantly more likely to engage in social media use, and they are more likely to use it for both inside and outside lobbying messages than all other types of groups. The paper ends with a discussion of the implications of these findings and directions for future research. Social media provides a unique and low-cost venue for interest groups to communicate their positions to a variety of audiences and theories of lobbying ought to consider the social media behavior of organizations in their analysis of interest group activity. 


\section{Inside and Outside Lobbying Strategies and the Groups that Use Them}

Large scale studies of lobbying behavior are most commonly based on surveys and interviews of interest groups. These studies have analyzed trends across broad categories of organizations, such as trade and other business associations, professional associations, labor unions, and public interest organizations or citizens' groups (Kollman 1998, Nownes and Freeman 1998, Schlozman and Tierney 1986, Walker 1991). Trade and other business associations are organizations representing companies or businesses, generally in a shared industry. Examples of these are the Aluminum Association and the National Women's Business Council. Professional associations, on the other hand, are groups of individuals who share a common profession or occupation. The American Political Science Association and the American Medical Association are examples of professional associations. Labor unions are organizations of workers that engage in collective bargaining, such as the National Writers Union and the American Postal Workers Union. The term "citizens' groups" is commonly used to refer to all groups that are focused on some identity or issue that is not primarily economic or professional in nature - this includes groups identified by age, gender, race, legal status, or a shared interest in an issue or activity, such as saving the environment (Schlozman and Tierney 1986, Walker 1991). While some studies break out public interest or nonprofit sector organizations separately, this paper will use the term in its more inclusive sense. Examples of citizens' groups under this definition include the National Association for the Advancement of Colored People (NAACP), the AARP, and the World Wildlife Fund.

Some lobbying activities are engaged in by virtually all organizations. For example, "testifying in hearings" and "contacting government officials directly to present your point of view" were found to be engaged in by $99 \%$ and $98 \%$, respectively, of organizations working at the federal level and 99\% and 97\% of organizations working at the state level (Nownes and Freeman 1998 , Schlozman and Tierney 1986). However, there is greater variability in other activities. Researchers often cluster types of activities together into "inside" and "outside" lobbying strategies. As Walker 
(1991) explained:

Some groups adopt an "inside" strategy based primarily upon close consultation with political and administrative leaders, relying mainly upon their financial resources, substantive expertise, and concentration within certain congressional constituencies as a basis for influence. Other groups become mainly dedicated to "outside" strategies based upon appeals to the public through mass media and efforts at the broad-scale mobilization of citizens at the grass roots.

Inside lobbying includes activities like testifying in committee and contacting policymakers directly, which, as noted above, are nearly universally engaged in by interest groups. It also includes less frequent activities such as contributing to campaigns, presenting research to government, and serving on public advisory boards. Outside lobbying includes activities like talking to the press, organizing letter-writing or email campaigns, publicizing voting records, endorsing candidates, running advertisements, and protesting or demonstrating (Kollman 1998).

Whether a group chooses an inside or outside strategy has been attributed to factors such as the type of membership the organization has, the sources of patronage available to it, the resources the group possesses, the degree to which the group's goals conflict with those of other organized groups, the salience of and support for the group's issue with the public, and which stage of the policy process the issue has reached (Kollman 1998, Walker 1991). Some of these are factors that are specific to each organization, and some are specific to the particular issue the organization is working on. Both are important. Even an organization that favors inside strategies may turn to the media or the public when they need outside pressure to give a policy an extra push over the finish line. Similarly, even organizations that are frequent users of outside strategies may not use them for every issue. However, the most consistent findings about strategy choice relate to the type of organization. Walker found "sharp differences" between groups in the profit sector - business and trade associations and professional associations - and citizens' groups in choice of strategies, with the former favoring inside lobbying and the latter preferring outside lobbying. Subsequent studies 
have found similar patterns, though the differences are not always so sharp (Grossmann 2012 , Kollman 1998). Notably, this pattern is not confined to the US, but has been documented in other countries as well, including Denmark, Austria, Germany, Ireland, Latvia, and Spain (Binderkrantz 2008, Dür and Mateo 2013).

There are a number of reasons why citizens' groups are more likely to use outside strategies than business and professional groups. First, as Schattschneider (1975) argued, groups with less power often need to expand the conflict in order to win. By educating the public about their issues and mobilizing those who share their views, citizens' groups can better counter wealthier, better connected business and professional groups (Walker 1991). Second, greater salience and lower complexity are two factors that help to predict outside lobbying (Junk 2016). Many of the issues that business and professional groups lobby on are highly technical, such as specific regulatory standards and licensing requirements. These issues are not likely to be of interest to a broad audience, and even if they were, members of these groups may believe that involving the public would muddy the waters more than it would help. Third, citizens' groups' success has been linked to public opinion (Hanegraaff and Poletti 2019). Neither type of strategy is inherently more or less likely to be successful. The success of both inside and outside lobbying approaches is conditional on other factors, including whether groups are working in coalitions and the type and popularity of the policy issue (De Bruycker and Beyers 2019).

\section{Social Media and Political Activity}

Social media provides an additional tool on which interest groups can pursue both inside and outside lobbying strategies. Twitter and Facebook (among other sites like LinkedIn, YouTube, Google+, Reddit, or even MySpace) have opened up new channels for two-way communication with both the public and politicians (Gainous and Wagner 2014, Golbeck, Grimes and Rogers 2010, Heiss, Schmuck and Matthes 2019, Rackaway 2014, Sørensen 2016, Tumasjan et al. 2011, Van der Graaf, Otjes and Rasmussen 2016). Moreover, communication through Facebook and

Twitter specifically may feel more personal and intimate than many other channels, due to the 
increased potential for direct communication with other accounts as compared to more traditional methods of communication (Johnson 2011).

Serious politicians recognize the value of social media and use it regularly. Twitter is the most popular platform among members of Congress, and its use is near universal; $100 \%$ of sitting U.S. Senators tweeted at least once during 2019.1 Facebook is the second most popular social media platform among members of Congress. According to the Pew Research Center, the median member of Congress tweeted 107 times per month during the first 5 months of 2020, and posted to Facebook 49 times per month. ${ }^{2}$ These rates have grown dramatically since 2016, when the median member of Congress tweeted 59 times per month and posted to Facebook 33 times per month. Democrats are much more active than Republicans on Twitter, but the parties' activity levels on Facebook are roughly the same. Because policymakers are frequent users of social media, interest groups could use these platforms to target messages directly to them - an online version of inside lobbying. Moreover, barriers to access are lower online. Twitter and Facebook are free services and can be used from anywhere in the world. An interest group representative need not be in Washington, D.C., or in the member's district to have a social media interaction with a policymaker.

Despite its potential for direct communication with policymakers, the few studies of interest groups' use of social media suggest that it is more commonly a tool for outside lobbying. Chalmers and Shotton (2016) found that the more an interest group organization focuses on shaping the public debate and the more it uses indirect (outside) lobbying techniques, the more likely it is to be active on social media. Obar, Zube and Lampe (2012) found that advocacy organizations believe social media is most useful for educating and engaging citizens. Two other small studies of American nonprofits found that these organizations used Facebook and Twitter primarily as a tool for one-way information sharing with members and the public, activities more in line with outside

\footnotetext{
${ }^{1}$ See, Statistica, Social Media and Politics in the United States https://www.statista.com/topics/3723/ social-media-and-politics-in-the-united-states/.

${ }^{2}$ Pew Research Center, "Congress Soars to New Heights on Social Media," July 16, 2020, https://www. pewresearch.org/internet/2020/07/16/congress-soars-to-new-heights-on-social-media/.
} 
lobbying than inside lobbying (Bortree and Seltzer|2009, Lovejoy, Waters and Saxton|2012).

There is some evidence that interest groups use social media for different types of lobbying across different platforms. Obar, Zube and Lampe (2012) found that advocacy organizations favored Facebook for facilitating civic engagement and collective action. A study of Norwegian interest groups working in the health care sector found that organizations used Facebook for a wide range of activities, including educating the public and their membership, attracting members and funders, and mobilizing political action (Figenschou and Fredheim 2020). They used Twitter as a tool for direct communication with policymakers and other stakeholders. However, because Twitter interactions are also visible to the public, organizations viewed it as a unique "middlestage" lobbying platform that can involve both inside and outside lobbying in the same message (Figenschou and Fredheim 2020, 6).

In sum, the relatively few existing studies of interest group use of social media for advocacy activities suggest that overall, organizations are more likely to use social media for outside lobbying activities than inside lobbying activities. Further, the logic that leads citizens' groups to be more active than business and professional groups in outside lobbying is not obviously altered by a move to a digital environment. Therefore, we expect that citizens' groups will be more active on social media than business and professional groups. We also expect that citizens' groups will be more likely to use social media for lobbying purposes, and that use will primarily be for outside lobbying. We expect that business and professional groups will use social media less frequently, and will primarily use social media to build and maintain relationships with stakeholders and policymakers.

\section{Data Collection}

Although some studies have examined interest groups' use of social media for inside and outside lobbying purposes, most have considered European contexts (e.g. Chalmers and Shotton 2016, Figenschou and Fredheim 2020) or very small samples (100 organizations or fewer) of American interest groups (Bortree and Seltzer 2009, Lovejoy, Waters and Saxton 2012). Our pa- 
per investigates these questions in the American context, using a much larger sample of American interest groups and their activity on two social media platforms. We assembled an original dataset of over 6 million social media posts on Twitter and Facebook from more than 1,500 interest groups active in lobbying at the federal level. To our knowledge, this is the first study of so large a quantity of individual interest group posts on those two platforms. It provides a unique opportunity to not only examine how interest groups use social media, but also how (and whether) that activity differs across Facebook and Twitter. Facebook and Twitter were selected because they are the two most popular social media platforms with policymakers, and the authors were able to access these unique data. The first step in our data collection was to identify an broad sample of interest groups that include representation across all of types of organizations usually studied.

\subsection{Organization Selection and Coding}

To identify interest group organization for analysis, we started from the list of over 1,700 advocacy organizations compiled by Grossmann (2012). We verified that the organizations were still active by checking their websites. For organizations that no longer had active websites, we did further web searches that sometimes identified other organizations that had absorbed the original organization or stepped into the space left by an organization that had become defunct. We also consulted lists of leading trade associations, professional associations, and citizens' groups to identify organizations not included in the Grossmann (2012) data. ${ }^{3}$ This process resulted in a list of 1,691 organizations currently active in lobbying the U.S. federal government. This list then was hand-coded into four discrete categories:

Business and Industry Groups are trade associations and other organizations that aggregate the different business sectors. Our list of active organizations includes $\mathbf{3 2 6}$ organizations in this category.

\footnotetext{
${ }^{3}$ Sources for these lists included: A Wikipedia list of trade associations: https://en.wikipedia. org/wiki/List_of_industry_trade_groups_in_the_United_States, The Reference for Business list of the largest professional associations: https://www.referenceforbusiness.com/encyclopedia/Per-Pro/ Professional-and-Trade-Organizations.html; and UCLA'S Civil Rights Project's list of leading civil rights groups: https://www.civilrightsproject.ucla.edu/resources/civil-rights-organizations
} 
Professional Organizations are organizations that are centered around a particular profession or occupation. Our list of active organizations includes $\mathbf{5 3 3}$ organizations in this category.

Unions are labor unions that bargain collectively on behalf of workers. Our list of active organizations includes 68 organizations in this category.

Citizens' Groups are organizations that centered around identities or issues that are not primarily economic or professional in nature. Our list of active organizations includes 763 organizations in this category.

\subsection{Facebook Data Collection}

Facebook gives groups an opportunity to communicate text, links, embedded videos, events, and other posts without the need to limit the volume of communication that is involved in other platforms, like Twitter. However, Facebook data had been relatively difficult to access before the advent of the program CrowdTangle. CrowdTangle is a Facebook tool that was initially piloted in 2019. It is designed to help researchers, journalists, and others follow and analyze public content on Facebook (i.e. public pages and groups). Previously, academics had used this tool to study topics like Russian involvement in African social media; the rise of right-wing politicians in Sweden; and the spread of health misinformation on Facebook (e.g. Berriche and Altay 2020, Grossman, Bush and DiResta 2019, Larsson 2019). Only in 2020 did Facebook open this tool up to a broader category of academics — and even then, academics must apply or be invited to access the data. CrowdTangle provides a wealth of data - when a post was created, the type of post, how many interactions a post received, how many shared the post, and the likes for each page at the time the post was created - for publicly available posts and pages..$^{4}$

We use the CrowdTangle tool to track the public pages of the organizations identified through the process above. Of the 1,691 organizations identified above, 1505 of them (89\%) had an easily identifiable Facebook page (see below for analysis of who is likely to have a Facebook

\footnotetext{
${ }^{4}$ It does not track post impressions, stories, demographic content on users, posts from private accounts, text of comments, and the identity of commenters.
} 
page). Once we identified those pages, we used the CrowdTangle tool to pull in all posts made by the groups from October 17, 2016 to August 17, 2020, the date of the first data pull [5 This pull resulted in a dataset of over 2 million Facebook posts made by these organizations, ranging from regular text posts to photos to YouTube links and event postings. We then linked the CrowdTangle database with our organizations database, which contains information on the group type, their age, and other variables. 6

\subsection{Twitter Data Collection}

As with Facebook, Twitter offers a useful and low-cost tool for political actors and advocacy groups to achieve their communication goals. It provides a platform where groups can post frequently and respond to events and other users in real time. Some of the most useful "affordances", or features, of Twitter are the use of hashtags (\#), mentions (@), and the ease of retweeting (i.e. sharing) tweets. Hashtags are used to reference and engage with online discussions on specific topics across users. Mentions allow one user to easily name another (such as a member of Congress) by handle, and, importantly for these organizations, the other user is notified. Retweets allow a user to share the entirety of another user's tweet, as well as comment on the post. All three are tools which are strategically and commonly used on Twitter generally, and may help organizations as they engage in lobbying activities online.

As researchers, Twitter is a relatively accessible data source to scrape using its API (application programming interface) if you have a user's handle, or their unique Twitter username. With the handle, a scholar can scrape information about an account, its most recent 3,200 tweets, as well as its followers.7 $]^{7}$ We collected the Twitter handle of each organization, identified as outlined above, using links from each organization's website and Google. Of the 1,691 organizations,

\footnotetext{
${ }^{5}$ We chose October 17, 2016 as the beginning of our data as it is just prior to the 2016 election.

${ }^{6}$ Out of the 1505 groups with a Facebook page, 41 of them could not be matched to the organization database because the Facebook page did not have a username attached to it. Usernames (unique identifiers on Facebook for organizations and pages) are optional, so while the vast majority of pages chose to create one, 41 of them did not.

${ }^{7}$ We used the rtweet package in R. The 3,200 tweet limit is set by the Twitter API. If an account has tweeted more than 3,200 times it will scrape the 3,200 most recent; if it has tweeted less than that threshold, it will return all tweets.
} 
1,535 of them had a Twitter account- just under 91\%. For each of these organizations, we collected several pieces of information about each account and its posts. This includes, but is not limited to, the organization's number of followers and total number of tweets, as well as the text of each tweet, the number of likes and retweets it has, and its time of creation down to the second. In total, we scraped 4,029,077 unique tweets by these organizations. 8 We focus the following analyses from October 17, 2016 to August 22, 2020. Doing so allows us to maintain consistency with the Facebook data and high levels of data coverage across the organizations.

\subsection{Keyword Dictionary}

With over 2 million Facebook posts and 4 million tweets, over 6 million organization posts in total, the text data that we have collected for this project is of too large of a scale for us to effectively or practically use, learn from, and analyze by hand. As a first step to assessing organization behavior on these platforms, we chose a dictionary approach. A dictionary is a collection or words or phrases which share a common theme and can be used to classify data- here, we classify the topic of Facebook posts or tweets. Using a dictionary for this text analysis task is a relatively simple way to extract tweets around a known topic. A dictionary is composed of several "strings" (words), and a post is coded as being related to a given topic if it includes at least one of the words in the dictionary for that topic.

We began by hand-coding a sample of 150 Facebook posts and 200 tweets. These posts and tweets were coded for whether they were most consistent with inside lobbying, outside lobbying, both or neither. Posts and tweets were coded as inside lobbying if they tagged a policymaker in an attempt to engage them in dialog or if they appeared to directly address a policymaker in some other way. Within the hand-coded posts, this most often took the form of thanks to a policymaker and highlighting a connection between the policymaker and the organization. For example, organizations would thank a member of Congress for introducing bills they support. This has the

\footnotetext{
${ }^{8}$ Several of the interest groups created their Twitter accounts as early as 2008 and have tweeted more than 10,000 times since; due to Twitter's API limits we do not have coverage of their earliest tweets.
} 
dual effect of making a positive connection with the member and reaffirming their support for the legislation. Other examples include posts of photos of visits between an organization's members and policymakers, affirming the relationship and their shared interest in an issue. These posts look slightly different on Facebook and Twitter. Twitter allows organizations to easily tag the policymakers they are referencing, which notifies the policymakers of the post and allows them to easily respond. In contrast, on Facebook, you can only tag a policymaker if their public page or account allows it. None of the posts in the hand-coded Facebook sample included tags of policymakers. Thus, these posts would only be effective as inside lobbying if the policymaker follows the organization's account or came across the post in some other way. Figure 1 provides an example of a tweet and a Facebook post coded as inside lobbying. The Facebook example highlights the National Fraternal Order of Police's post praising President Trump, typical of this type of lobbying that targets policymakers. The Twitter example shows the Military Officers Association of America meeting with a particular lawmaker, documenting and reaffirming the relationship.

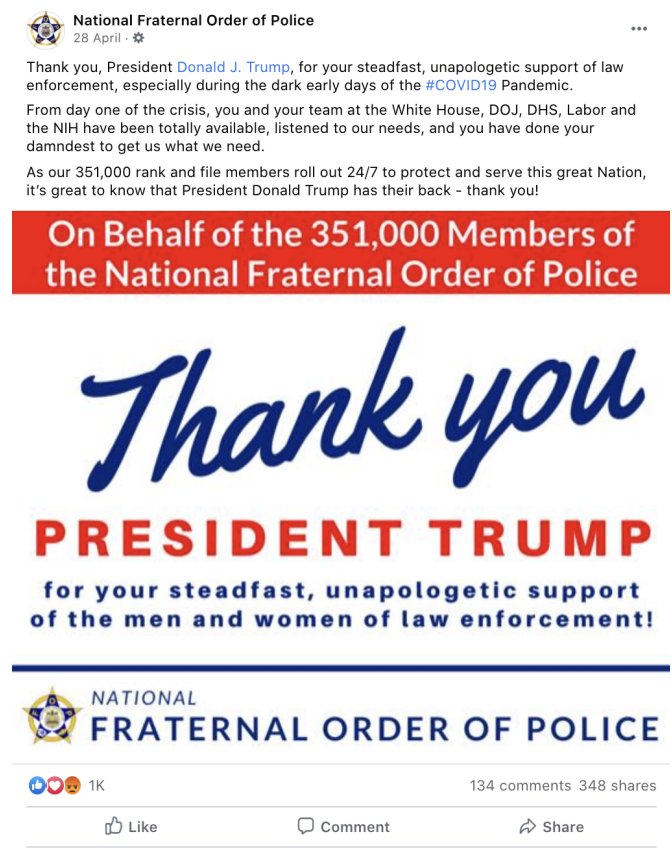

(a) Facebook Example of Inside Lobbying
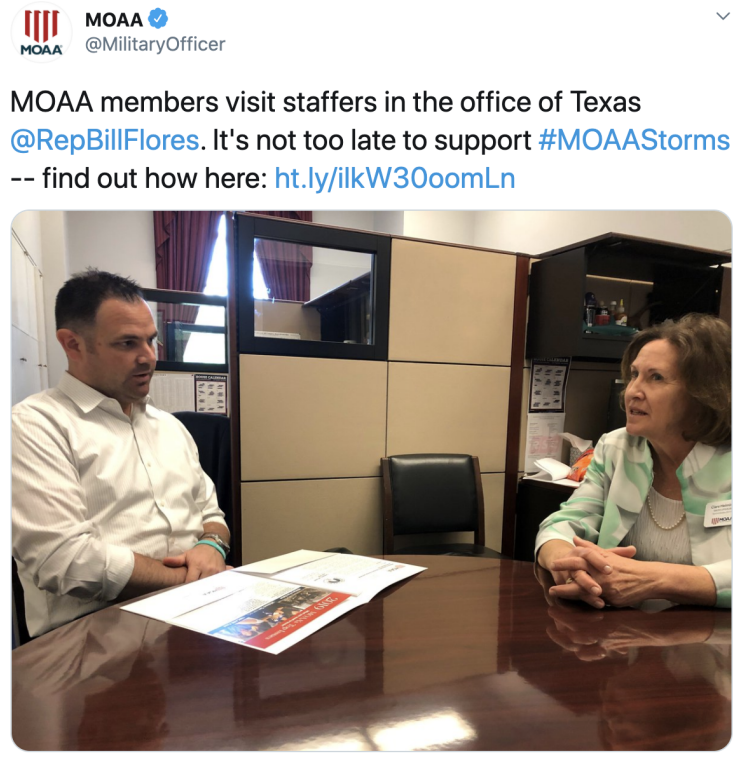

7:31 PM · Apr 10, $2019 \cdot$ Hootsuite Inc.

(b) Twitter Example of Inside Lobbying

Figure 1: Example of posts coded as inside lobbying on Facebook $\sqrt{1 \mathrm{a}})$ and Twitter $(1 \mathrm{~b})$.

Posts and tweets were coded as outside lobbying if they appeared to address the organiza- 
tion's members or the public, and provided educational information about a policy issue and/or a call to action about that policy. Most of these posts and tweets provided general policy information, and seem aimed at raising awareness or knowledge about an issue. Calls to action were less common in the hand-coded sub-samples, though they did occur. Figure 2 provides an example tweet and post coded as outside lobbying. The Facebook example is from the National Resource Defense Council, and it highlights problems at the Environmental Protection Agency to educate its members and the public. The Twitter example raises concerns about a treaty that is important Audobon Society members and asks those members to take action to save it.

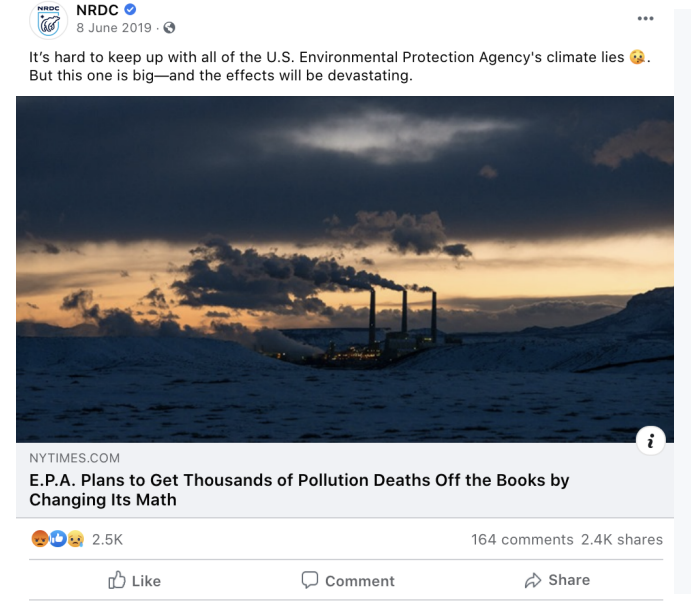

(a) Facebook Example of Outside Lobbying

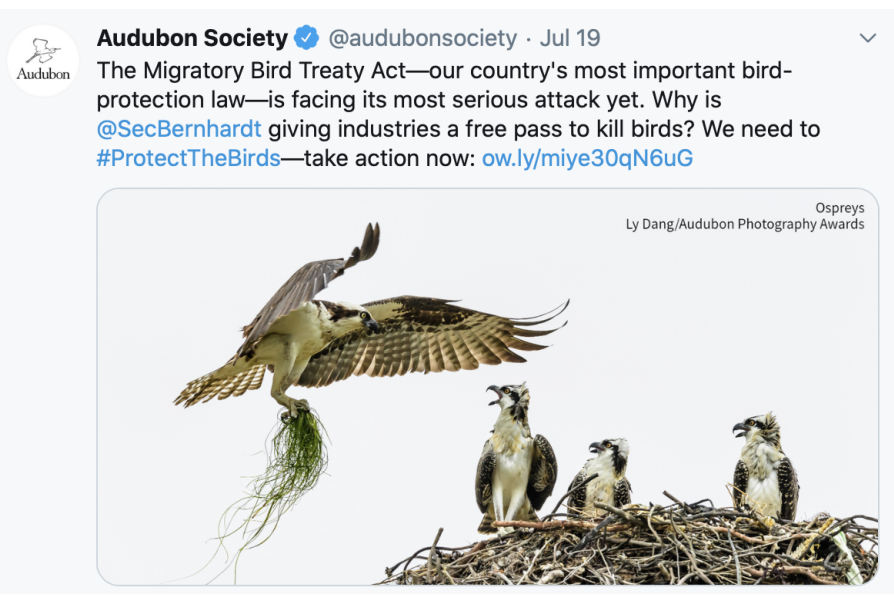

(b) Twitter Example of Outside Lobbying

Figure 2: Example of posts coded as outside lobbying on Facebook $2 \mathrm{a}$ ) and Twitter $2 \mathrm{~b}$.

Some posts and tweets contained elements of both inside and outside lobbying, illustrating the "middle stage" discussed by Figenschou and Fredheim (2020). These posts were coded as both inside and outside lobbying. Figure 3 provides examples. The Facebook example shows the National Taxpayers Union crediting Senators Cruz and McSally for introducing legislation the organization supports and also provides more information on the bill for members' education. Similarly, the Twitter example thanks bipartisan members of Congress for introducing legislation and provides more information about bill. Almost half of the posts and tweets hand-coded as inside lobbying also contained elements of outside lobbying.

Finally, many posts and tweets were coded as not lobbying related. These often concerned 
member benefits or training opportunities that were not policy related. Some were fundraising appeals, and others provided public education, like advice for staying safe from Covid-19, not tied to a particular policy initiative.

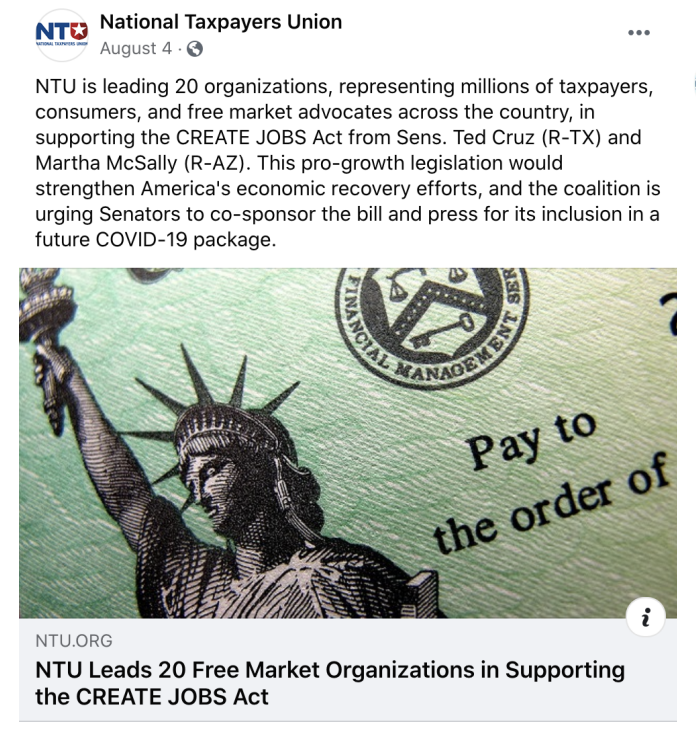

(a) Facebook Example of Inside and Outside Lobbying
American Psychological Association @APA · Feb 4, 2019

"We applaud @RepJudyChu, @RepJasonSmith, @janschakowsky, \& @RepMullin for their bipartisan leadership in working to remove an unnecessary barrier to psychological services." -- APA CEO @ArthurCEvans

More about the Medicare Mental Health Access Act: on.apa.org/2BIVg19

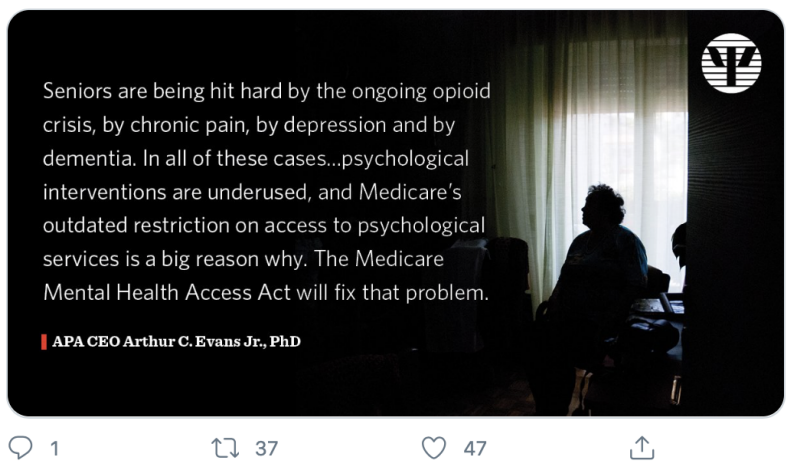

(b) Twitter Example of Inside and Outside Lobbying

Figure 3: Example of posts coded as both inside and outside lobbying on Facebook $(3 \mathrm{a})$ and Twitter (3b).

Using keywords identified through the hand-coded samples, we created a dictionary list of terms for first, posts we identified as lobbying (as opposed to member outreach or other activities) and second, for posts we identified as inside or outside lobbying. We used this dictionary to create a series of dummy variables for whether the posts involved any lobbying activity at all and also, whether that lobbying activity was inside (aimed at policymakers) or outside (aimed at the media or the public). Lobbying terms include words like administration, justice, and Kamala Harris, whereas non-lobbying terms include \#GivingTuesday, mission, and donate. In general, inside lobbying terms included words or phrases like administration, justice, Kamala Harris, Trump, or president. On the other hand, outside lobbying terms included words or phrases like conversation, elections, policy, action, priorities, and safety. 


\section{Comparing Twitter and Facebook}

In addition to allowing us to analyze our hypotheses in the next section, this wealth of social media data from both Facebook and Twitter allows us to descriptively illustrate how different kinds of groups are using the platforms differently. Figure 4 highlights the sum of daily posts by our sample of advocacy organizations on Facebook (Figure 4a) and Twitter (Figure 4b). The Facebook posts represent all those contained in the CrowdTangle data for each day between October 17, 2016 to August 17, 2020, grouped by organization type. We see patterns based on group type: citizens' groups, for example, post the most out of our group types, followed by professional groups, business and industry organizations, and finally unions. There also appears to be a seasonality to

the posts, with more created on days in the spring and summer and relatively fewer created on days in the fall and winter. While we do not have a clear explanation for why this seasonality might exist, it is evidence of strategic posting by these groups, with organizations posting more often on certain days, months, or times of year than others.

We can see similarities and differences between Figure $4 \mathrm{a}$ and Figure $4 \mathrm{~b}$, which includes all tweets by the organizations posted in the same time period, from October 17, 2016 to August 22,2020 . The same ordering of tweet frequency by group type is the same - the most frequent tweeters were citizens' groups, then professional organizations, business and industry groups, and unions. Though the organizations posted hundreds to thousands of times each day across both platforms, they did so at a larger scale on Twitter. Interestingly, the seasonality noted in the Facebook data is present in the Twitter data too, particularly around fall and winter. The frequency with which most groups posted on Facebook remained relatively stable in comparison to Twitter, aside from the aforementioned seasonality across both. This pattern is most obvious for citizens' groups, where the overall number of daily posts increased from about 1,500 to almost 4,000 from January 2019 to August 2020, but also exists for professional organizations.

Next, we can compare the summary statistics for these two social media platforms. Table 1 contains the summary statistics for the CrowdTangle data for this time period. While some pages 


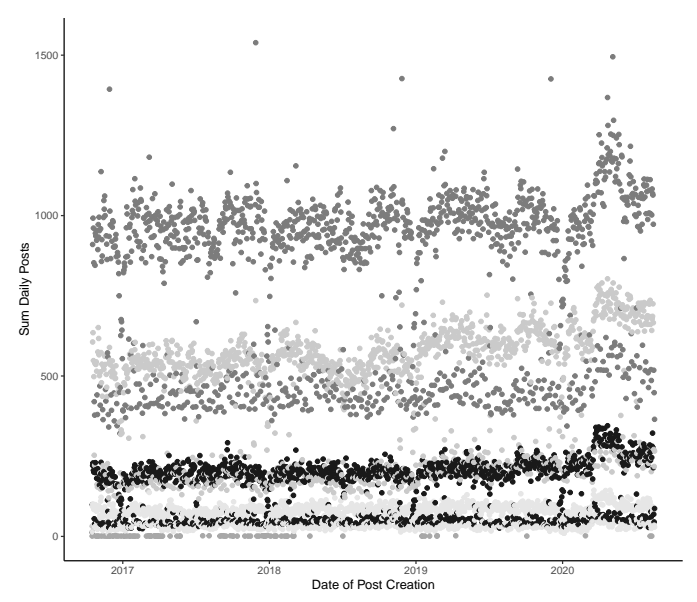

(a) Facebook

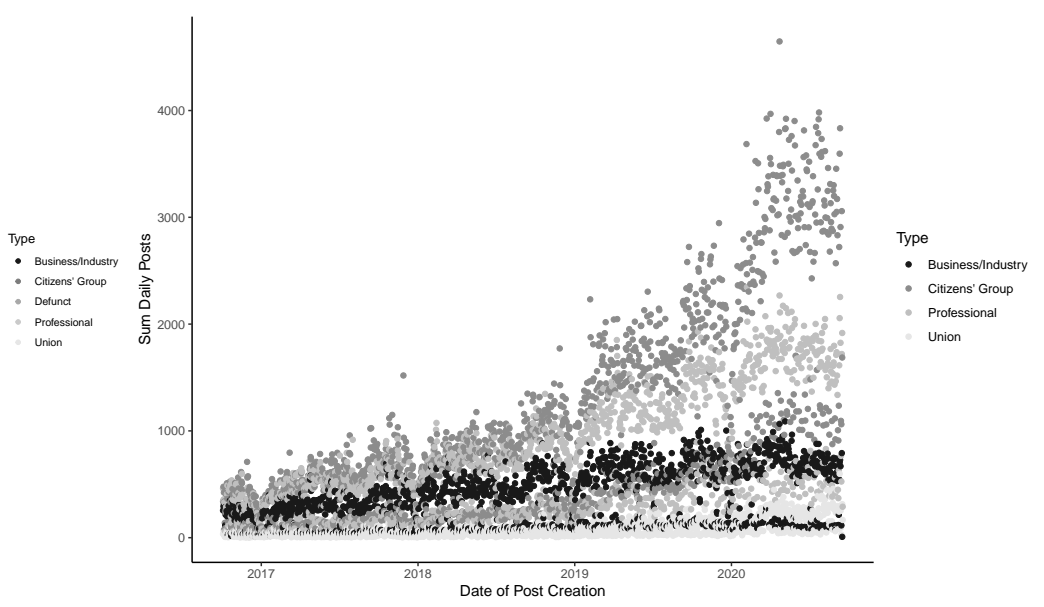

(b) Twitter

Figure 4: Sum daily posts of advocacy groups by group type. Figure 4a is Facebook posts from October 17, 2016 to August 17, 2020. Figure 4b are Tweets from October 17, 2016 to August 22, 2020.

have more than 7 million likes (NumbersUSA, an anti-immigrant group), the average organization has about 300,000 likes and one organization had only one like at the time of the post creation (American Council on Education). Similarly, the post likes are highly variable. Some posts receive no likes at all (a post from the National Medical Association about their annual meeting's allergy section program), while others receive more than 700,000 (a post from AARP about father and son veterans battling coronavirus at the same time). Finally, $11 \%$ of posts are made by business organizations; $55 \%$ by citizens' groups; $30 \%$ by professional organizations, and only $4 \%$ by union groups. This comports with the graphical patterns from Figure $4 \mathrm{a}$ and provides prima facie evidence for differential use of Facebook by group type.

Table 1: Facebook CrowdTangle Summary Statistics, October 17, 2016 to August 17, 2020

\begin{tabular}{lccccccc}
\hline \hline Statistic & $\mathrm{N}$ & Mean & St. Dev. & Min & Pctl(25) & Pctl(75) & Max \\
\hline Page Likes & $1,688,863$ & $294,528.00$ & $659,189.90$ & 1.00 & $13,044.00$ & $235,237.00$ & $7,298,566.00$ \\
Post Likes & $2,135,771$ & 182.51 & $1,771.04$ & 0 & 3 & 54 & 708,619 \\
Business Org. & $2,106,228$ & 0.11 & 0.31 & 0.00 & 0.00 & 0.00 & 1.00 \\
Citizens' Org. & $2,106,228$ & 0.54 & 0.50 & 0.00 & 0.00 & 1.00 & 1.00 \\
Professional Org. & $2,106,228$ & 0.31 & 0.46 & 0.00 & 0.00 & 1.00 & 1.00 \\
Union Org. & $2,106,228$ & 0.05 & 0.21 & 0.00 & 0.00 & 0.00 & 1.00 \\
\hline
\end{tabular}


Table 2 shows the summary statistics for the Twitter sample. As with the CrowdTangle data, thousands of users follow these organizations on Twitter. The average number of followers is about 70,000, more than four times less than the average number of page likes on Facebook, the maximum number of followers is almost 4.5 million (Human Rights Watch), and the minimum is only 22 (The Retired Enlisted Association). There is also similar variation in the overall number of tweet favorites as with Facebook post likes - the majority receive at most a handful of likes, while some received hundreds of thousands of favorites. The tweet with the most favorites, nearly 654,000, was made by the Record Industry Association of America (RIAA) and was about the KPop band BTS. Turning to the breakdown of posts by organization type, we find results consistent with those presented in Figure 4 and Facebook summary statistics in Table 1 . Citizens' organizations make up the largest share of tweets at $46 \%$, followed by professional organizations at $32 \%$, business groups at $18 \%$, and unions at just $4 \%$. We find evidence that there are differences in the frequency with which these types of organizations use Twitter as well as Facebook.

Table 2: Twitter Summary Statistics, October 17, 2017 to August 22, 2020

\begin{tabular}{lccccccc}
\hline \hline Statistic & $\mathrm{N}$ & Mean & St. Dev. & Min & Pctl(25) & Pctl(75) & Max \\
\hline Number Followers & 751,860 & $69,523.10$ & $401,336.00$ & 22.00 & $4,488.00$ & $28,563.00$ & $4,429,590.00$ \\
Post Favorites & $4,029,077$ & 13.62 & 595.93 & 0 & 0 & 4 & 653,546 \\
Business Org. & $4,029,077$ & 0.18 & 0.38 & 0 & 0 & 0 & 1 \\
Citizens' Org. & $4,029,077$ & 0.46 & 0.50 & 0 & 0 & 1 & 1 \\
Professional Org. & $4,029,077$ & 0.32 & 0.47 & 0 & 0 & 1 & 1 \\
Union Org. & $4,029,077$ & 0.04 & 0.19 & 0 & 0 & 0 & 1 \\
\hline
\end{tabular}

\section{Analysis of Hypotheses}

We next turn to the explicit analyses of our hypotheses. Recall that our hypotheses are: citizens' groups will be more active on social media than business and professional groups; business and professional groups will use social media less frequently and will use primarily to build and maintain relationships with stakeholders and policymakers; citizens' groups will be more likely to use social media for lobbying, and outside lobbying in particular; and finally, organizations are more likely to use social media for outside lobbying than inside lobbying. We consider each of 
these hypotheses in turn below.

\subsection{Are Certain Organizations More Likely to Have a Social Media Page?}

Are certain kinds of groups more likely to have social media pages at all? To analyze this question, we run a series of straightforward difference in means t-tests on our Facebook and Twitter data separately. We first consider Facebook, comparing the percent of business and industry groups on our master list with a Facebook page to the percent of citizens' groups with a Facebook page (recall that $89 \%$ of groups overall had an easily identifiable Facebook page). These results are in Table 3.

\begin{tabular}{rrlr}
\hline & t.statistic & Confidence.Interval & p.value \\
\hline $\mathrm{t}$ & -1.97 & $-0.09,0$ & 0.05 \\
\hline
\end{tabular}

Table 3: Results from a Welch Two Sample t-test. Approximately 84.31 percent of business and industry groups have a Facebook page, compared to approximately 88.87 percent of citizen's groups.

This test provides initial evidence that different types of groups are engaging with Facebook at different rates. While only about $84 \%$ of business groups from our master list had a Facebook page, nearly $89 \%$ of citizens' groups did. This provides initial evidence for one initial claim, that different types of organizations may not even create a Facebook post to begin with to engage in any lobbying or outreach activities. From Table 3 we can reject the null hypothesis of no difference in means for the percent of business and industry or citizens' groups that have a Facebook page.

We next completed the same test for organizations' existence on Twitter, by comparing the percentage of business and industry groups to citizens' groups who have Twitter pages. We present these results in Table 4. Unlike on Facebook, we do not find evidence that one type of organization is more or less likely to have a Twitter account than the other- both types have adoption rates around $90 \%$. As with Facebook, this still leaves $10 \%$ of groups across both types who have chosen to not use this social media platform to help them to achieve their goals.

The results from Tables 3 and 4 provide initial evidence that different types of groups use these two platforms differently. However, the differential results between them are puzzling as they 


\begin{tabular}{rrlr}
\hline & t.statistic & Confidence.Interval & p.value \\
\hline $\mathrm{t}$ & 1.14 & $-0.02,0.06$ & 0.26 \\
\hline
\end{tabular}

Table 4: Results from a Welch Two Sample t-test. Approximately 91.69 percent of business and industry groups have a Twitter page, compared to approximately 89.54 percent of citizen's groups.

would indicate organizations use some social media platforms but not others. Are the advocacy groups in our sample more likely to have a Facebook or Twitter page? Next, we conduct another t-test to compare the percent of all groups with either a Facebook or Twitter. Table 5 lists the results of this t-test.

\begin{tabular}{lrlr}
\hline & t.statistic & Confidence.Interval & p.value \\
\hline $\mathrm{t}$ & -1.69 & $-0.04,0$ & 0.09 \\
\hline
\end{tabular}

Table 5: Results from a Welch Two Sample t-test. Approximately 88.79 percent of groups have a Facebook page, compared to approximately 90.56 percent of groups have a Twitter.

The advocacy groups in our sample are significantly more likely (at a significance level of $p<0.1)$ to have a Twitter page than a Facebook page, interestingly. Coupled with the t-test results from Tables 3 and 4 , Table 5 suggests that business and industry groups may be driving this difference in use of the different social media platforms, as they are less likely to have a Facebook presence but no more or less likely to have a Twitter page.

\subsection{Inside and Outside Lobbying}

Next, we explore the characteristics of this engagement on social media. Who are the groups targeting when they post on Facebook? To analyze this, we rely on the keyword coding process as described above to roughly code the Facebook or Twitter posts into inside or outside lobbying..$^{9}$ We calculate the percent of daily posts that first, contain any lobbying activity; second, contain inside lobbying activity; and finally, contain outside lobbying activity. Figure 5 contains this information for the daily Facebook data.

Figure 5a highlights that approximately $50 \%$ of daily posts contain some sort of lobbying

\footnotetext{
${ }^{9}$ Our next step is to conduct this process using a supervised topic modeling approach. In this way, we will be better able to capture and classify the nuanced differences between different lobbying tactics.
} 


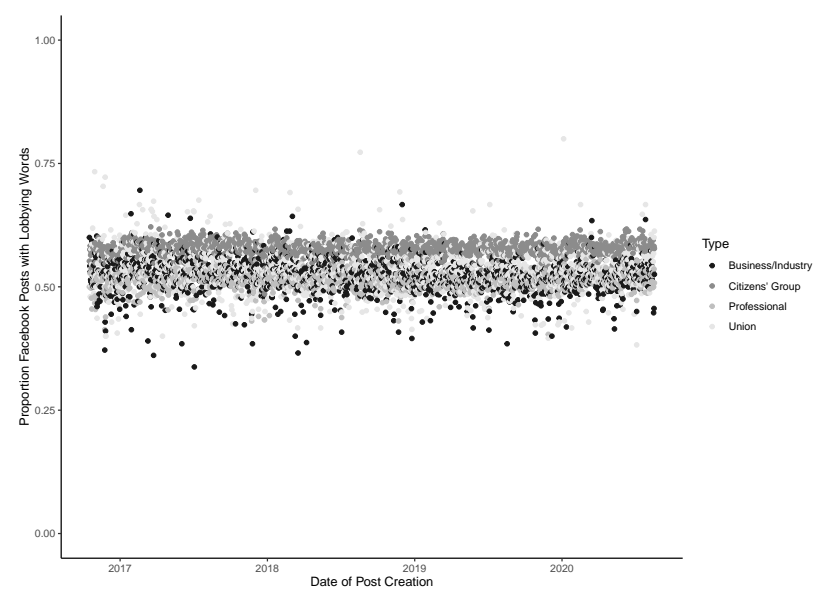

(a) Lobbying Frequency

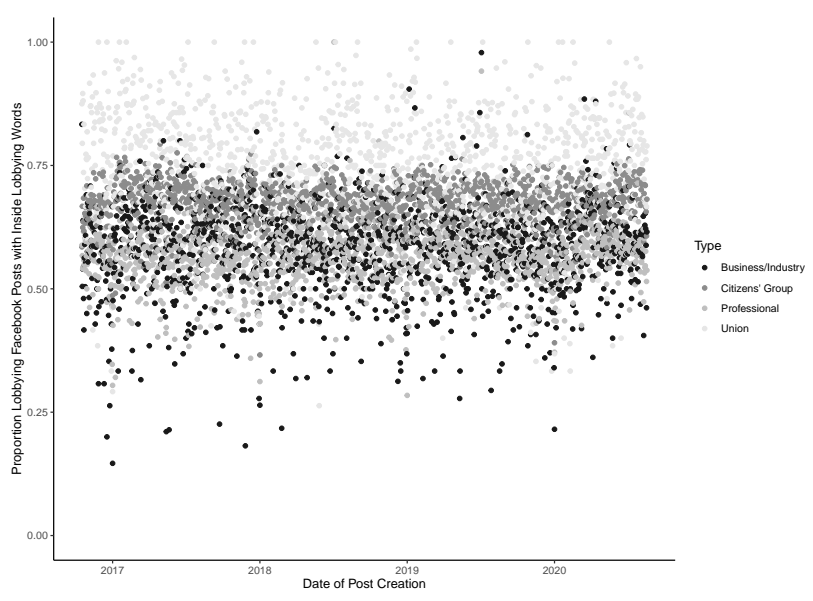

(b) Inside Lobbying Frequency

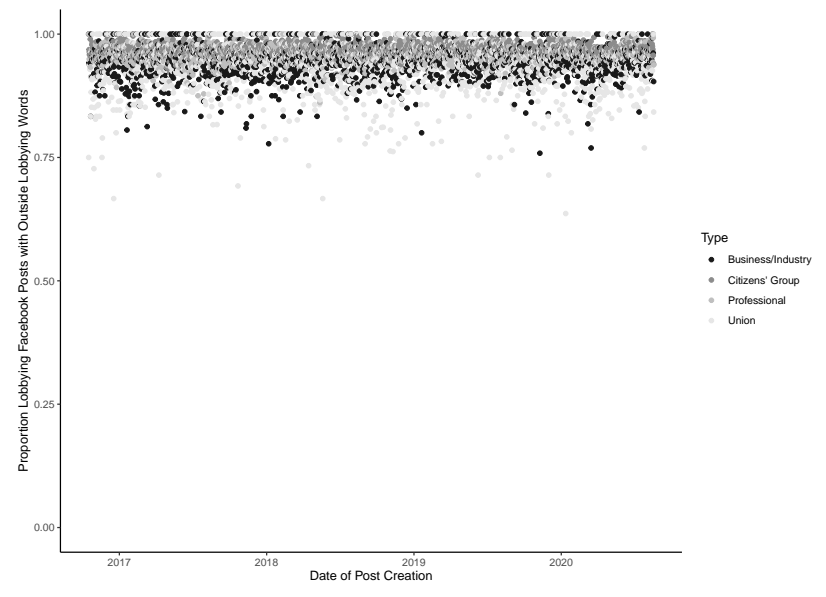

(c) Outside Lobbying Frequency

Figure 5: Proportion of daily Facebook posts by group type that are devoted to lobbying (5a); inside lobbying (5b); and outside lobbying (5c).

activity, a fairly consistent percentage across groups. Though there is some variation - some groups devote only $30 \%$ of their daily activity on Facebook to lobbying (business and industry) and others devote more than $75 \%$ (unions) - there is a rough consistency across groups. However, Figure $5 \mathrm{~b}$ tells a different story for inside lobbying activity. Unions appear to devote most of their daily posts to inside lobbying (nearly or exactly 100\%), with business and industry devoting between 15 and about $90 \%$ of their daily Facebook activity to inside lobbying activities. Finally, Figure 5c highlights the vast use of Facebook for outside lobbying activities, nearly $100 \%$ of the coded posts. It is important to note, however, that these categories are not mutually exclusive: one post can be flagged as inside and outside lobbying per our keyword coding above, so one post may be able to 
accomplish inside and outside lobbying goals.

Who are the groups targeting when they post on Twitter? Figure 6 contains this information for daily tweets and is of the same structure as Figure 5 . Figure 6 a shows that approximately $60 \%$ of all tweets by the organizations can be classified as lobbying. This is largely consistent across groups, with the exception of some unions and business and industry groups, especially after 2018. It is also about $10 \%$ higher than the daily proportion of Facebook posts by the same groups over the same time period. We see the most variation across groups in Figure 6b, which shows the proportion of lobbying tweets which our dictionary labelled as referencing inside lobbying. Most groups across type spend $60 \%$ to $75 \%$ of their lobbying tweets on inside lobbying. Citizens' groups and professional organizations post a similar proportion of inside lobbying tweets, but unions cover the full range of possibilities — between $0 \%$ and $100 \%$ of their tweets, though many are $70 \%$ or higher- and business and industry ranges from about $10 \%$ to $100 \%$. In the final panel, Figure $6 \mathrm{c}$, we can see that across all organization types, a high proportion of their posts use outside lobbying tactics. As with Facebook posts, these two categories are not mutually exclusive and a single tweet can currently be labelled as both inside and outside lobbying. This is something that we will continue to deal with theoretically and logistically in future iterations of this project.

This initial examination highlights how even one social media post may be performing two purposes, targeting both administration and political audiences and public and media audiences simultaneously. In future iterations of this project, we will classify posts from both Facebook and Twitter using supervised topic models. This will allow us to better leverage the nuance of these topics, filter posts into unique inside or outside lobbying activity, and more accurately capturing those instances where a single post contains evidence of both strategies. We will train several classifiers to label all posts, using insights developed through a random subset of hand-labeled Facebook posts and tweets.

Our initial examination, though, next considers the estimation of this relationship empirically. Figures 5 and 6 indicate groups use these platforms to target various audiences and 


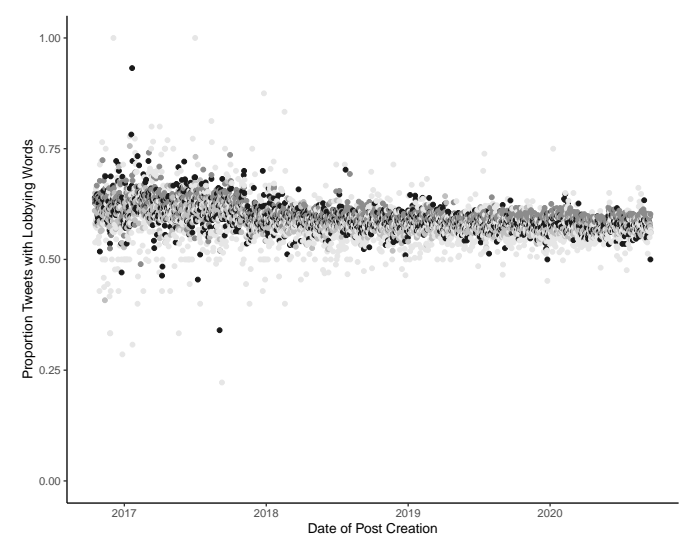

(a) Lobbying Frequency

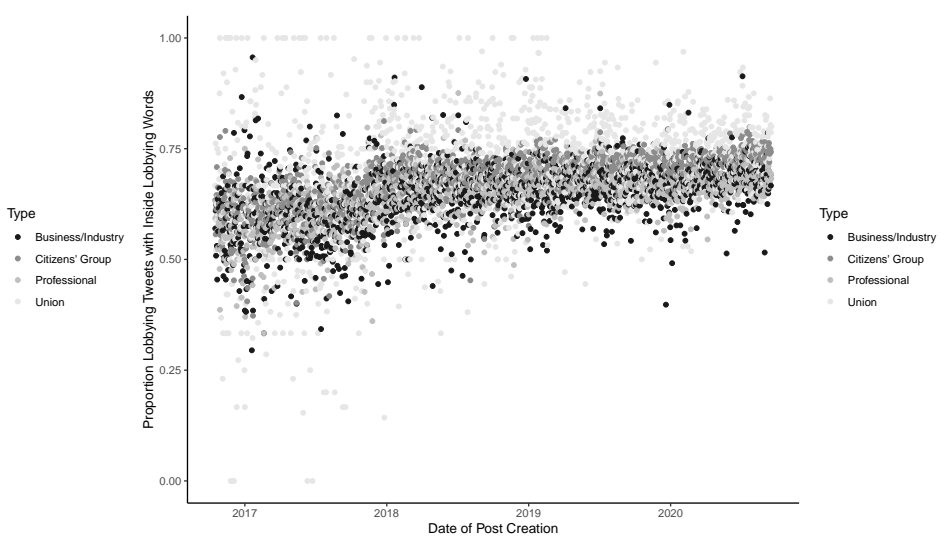

(b) Inside Lobbying Frequency

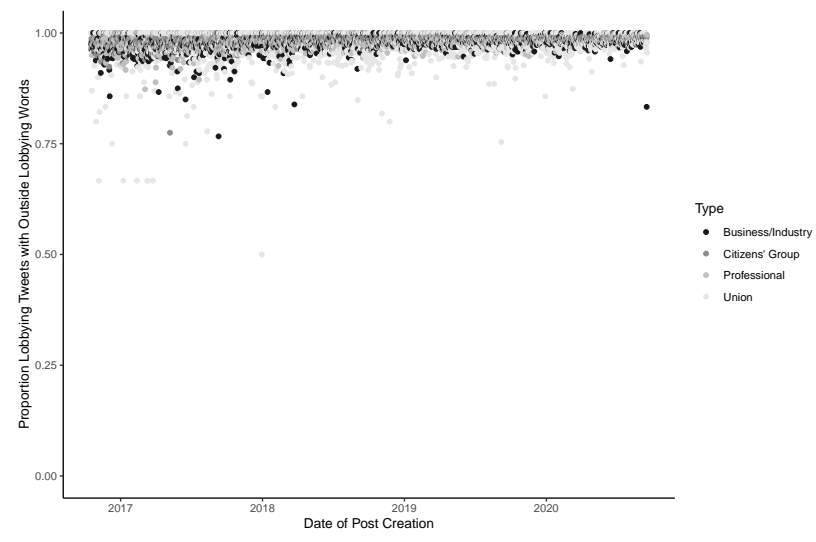

(c) Outside Lobbying Frequency

Figure 6: Proportion of daily tweets by group type that are devoted to lobbying 6a); inside lobbying $\sqrt[6 \mathrm{~b}]{ }$; and outside lobbying $(6 \mathrm{c})$.

next, we estimate this relationship using an ordinary least squares (OLS) regression seen in Equation 1 .

$y_{i, d}=\beta_{1}$ CitizensGroup $+\beta_{2}$ ProfessionalGroup $+\beta_{3}$ Union $+\beta_{4}$ LoggedLikes $+\beta_{5}$ Age $+\delta_{m}+\varepsilon_{i, d}$

In Equation 1, $y_{i, d}$ represents our three dependent variables, aggregated to the group typeday: percent of posts devoted to lobbying; percent of posts devoted to inside lobbying; and percent of posts devoted to outside lobbying (as in Figures 5 and 6 ). The main independent variables of interest are $\beta_{1}, \beta_{2}$, and $\beta_{3}$, dummy variables for citizens' groups, professional groups, or unions (business and industry groups are the excluded category in the below analyses). We also control for 


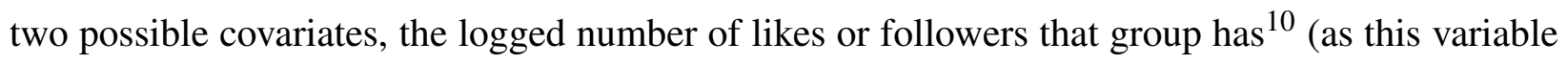
is massively skewed) and the age of that group. Finally, $\delta_{m}$ contains month fixed effects to reflect the seasonality of posts, seen in Figure 4.

Table 6 contains this estimation for the Facebook data. Compared to business and industry groups (the excluded category), citizens' groups are significantly more likely to engage in any lobbying, and inside or outside lobbying specifically. Professional groups, on the other hand, are less likely to engage in lobbying than business or industry groups, but more likely to post on inside and outside lobbying topics. Finally, unions are more likely to engage in inside lobbying than business organizations, though they are no more or less likely to post on any lobbying topic, or outside lobbying specifically. The covariates also provide some interesting insights into the lobbying activity of these groups. Pages with more likes, for example, are more likely to engage in any kind of lobbying and outside lobbying specifically, but less likely to post on inside lobbying topics. Organization age behaves similarly, with older groups more likely to engage in lobbying activity generally, but less likely to engage in inside or outside lobbying specifically.

Table 7 estimates Equation 1 on the Twitter data. As with the Facebook analysis above, business and industry groups are the excluded category. When compared to these, citizens' groups are more likely to engage in both inside and outside lobbying behavior, as well as lobbying overall. Professional groups are less likely to use their tweets to lobby generally and using inside lobbying strategies when compared to business groups, but there is not a statistically significant difference between the two types for outside lobbying. Similarly, unions are also less likely to lobby in their tweets than business and industry groups. However, they are more likely to engage in inside lobbying tactics and are not more or less likely to use outside lobbying in their posts. We can also consider additional features of the groups and their Twitter pages. The more followers that an organization has, the more likely they are to engage in inside lobbying, are less likely to use lobbying overall, but are not any more or less likely to post about outside lobbying. The older that

\footnotetext{
${ }^{10}$ Facebook provides a measure of the followers each time a post is created, so this is the average number of likes per group type-day. The Twitter data only provides a measure of followers at the time of the data scrape, so this is the number of followers by group-type day at the date of our scrape on August 18, 2020.
} 
Table 6: Daily Facebook Posts and Lobbying Activity by Group Type

Perc. Lobbying Perc. Inside Lobbying Perc. Outside Lobbying

\begin{tabular}{lccc}
\hline Citizens' Group & $0.054^{* * *}$ & $0.165^{* * *}$ & $0.013^{* * *}$ \\
& $(0.003)$ & $(0.009)$ & $(0.004)$ \\
Professional Group & $-0.014^{* * *}$ & $0.030^{* * *}$ & $0.015^{* * *}$ \\
& $(0.002)$ & $(0.006)$ & $(0.003)$ \\
Union & 0.0004 & $0.206^{* * *}$ & 0.008 \\
& $(0.004)$ & $(0.011)$ & $(0.005)$ \\
Logged Avg. Page Likes & $0.003^{*}$ & $-0.045^{* * *}$ & $0.005^{* * *}$ \\
& $(0.002)$ & $(0.005)$ & $(0.002)$ \\
Avg. Org. Age & $0.0003^{* * *}$ & $-0.001^{* * *}$ & $-0.0004^{* * *}$ \\
& $(0.0001)$ & $(0.0003)$ & $(0.0001)$ \\
$\mathrm{N}$ & 5,604 & 5,604 & 5,604 \\
$\mathrm{R}^{2}$ & 0.419 & 0.462 & 0.123 \\
Adjusted $\mathrm{R}^{2}$ & 0.413 & 0.457 & 0.115 \\
Residual Std. Error $(\mathrm{df}=5552)$ & 0.030 & 0.083 & 0.035 \\
\hline
\end{tabular}

${ }^{*} \mathrm{p}<.1 ;{ }^{* *} \mathrm{p}<.05 ;{ }^{* * *} \mathrm{p}<.01$

Business and industry groups is the excluded category.

Month fixed effects included. Data aggregated to the group

type-day.

an organization is, the more likely it is to engage in lobbying overall and inside lobbying, though there is no relationship between age and outside lobbying.

These results provide mixed support of our hypotheses. The hypothesis that predicted business and industry groups would be more likely to engage in higher levels of inside lobbying than citizens' groups is not supported by their behavior on Twitter. Citizens' groups are more likely than business organizations to use all types of lobbying in their posts. However, this also provides some evidence for another of our hypotheses, that citizens' groups use more outside lobbying tactics. As we use more sophisticated classification methods in the future, we expect them to allow us to better label lobbying posts as inside, outside, or both, and that doing so will clarify our results and our understanding of interest group behavior on social media. 
Table 7: Daily Twitter Posts and Lobbying Activity by Group Type

Perc. Lobbying Perc. Inside Lobbying Perc. Outside Lobbying

(1)

\begin{tabular}{lccc}
\hline Citizens' Group & $0.017^{* * *}$ & $0.033^{* * *}$ & $0.004^{* * *}$ \\
& $(0.002)$ & $(0.004)$ & $(0.001)$ \\
Professional Group & $-0.011^{* * *}$ & $-0.007^{*}$ & 0.001 \\
& $(0.002)$ & $(0.004)$ & $(0.001)$ \\
Union & $-0.020^{* * *}$ & $0.053^{* * *}$ & 0.002 \\
& $(0.003)$ & $(0.007)$ & $(0.002)$ \\
Log Average Page Likes & $-0.002^{*}$ & $0.005^{*}$ & 0.001 \\
& $(0.001)$ & $(0.003)$ & $-0.0001)$ \\
Average Org. Age & $0.0002^{* * *}$ & $0.0003^{* *}$ & $(0.00004)$ \\
& $(0.0001)$ & $(0.0001)$ & 5,718 \\
N & 5,718 & 5,718 & 0.049 \\
$\mathrm{R}^{2}$ & 0.249 & 0.262 & 0.040 \\
Adjusted $\mathrm{R}^{2}$ & 0.242 & 0.255 & 0.025 \\
Residual Std. Error $(\mathrm{df}=5665)$ & 0.034 & 0.086 & \\
\hline
\end{tabular}

${ }^{*} \mathrm{p}<.1 ;{ }^{* *} \mathrm{p}<.05 ;{ }^{* * *} \mathrm{p}<.01$

Business and industry groups is the excluded category. Month fixed effects included. Data aggregated to the group type-day.

\section{Discussion and Conclusion}

This paper investigates the lobbying behavior of organizations on Facebook and Twitter using a dataset of over 6 million posts. We explored which types of groups were most likely to use social media and whether these organizations were more likely to use social media for inside or outside lobbying. We expected that citizens' groups would be the most active on social media overall and for outside lobbying in particular; and finally, that business and professional groups would use social media less frequently but engage in more inside lobbying when they do use these platforms. We find initial, but not unmixed, support for these contentions. Citizens' groups are more likely to have a Facebook page than business or industry groups, but that is not the case for our Twitter data. These groups are also the most active at lobbying activity overall, and inside and outside lobbying specifically, on Twitter and Facebook. Business and industry groups do 
seem somewhat less active on social media. Overall, outside lobbying is the most common type of lobbying on social media, and citizens' groups are its most frequent users. This suggests that traditional patterns of lobbying are being replicated on social media platforms.

Our exploratory analysis lends credence to our hypotheses, but a more systematic categorization of social media posts will help illuminate these patterns more clearly. Will these relationships between group type and inside or outside lobbying activity persist once we use more precise keywords for our analysis or a supervised topic model? And, outside of the present analysis, what are the characteristics of this lobbying activity and does it differ across platforms? Do groups post the same content (potentially with different language or tone) on Facebook and Twitter? Our future systematic analyses may help to parse out some of these questions. Given the high number of posts that are currently getting coded as both inside AND outside lobbying, can we provide additional support for Figenschou and Fredheim s (2020) finding that social media can serve as a unique middle-stage form of lobbying, somewhere between inside and outside?

Nevertheless, the results here suggest a few important implications for the study of social media and interest groups. First, and most specifically, how does lobbying activity differ across platforms? We provide some initial evidence that these advocacy groups indeed use Twitter and Facebook differently and that these organizations are more likely to have a Twitter page than a Facebook page. Why? What are the characteristics of posts that make Twitter potentially more essential to groups' lobbying activity than Facebook? Future research ought to investigate these patterns - and even how activity on these two platforms can be paired with presence on other social media sites, like YouTube or Reddit.

More broadly, however, this paper encourages a reevaluation of how interest groups lobby. It is no longer the case that organizations need money and resources to create an ad, for example, if they can post on social media for free and generate interest in their cause from policymakers, the public, and their members. How then does social media fit in to our evaluations of lobbying activity? Is it more or less important than these traditional lobbying behaviors and how do groups 
evaluate these different platforms as important to their success? While we cannot provide concrete answers to these broad questions here, our paper does point to the vast and differential use of social media for advocacy groups. 


\section{References}

Berriche, Manon and Sacha Altay. 2020. "Internet users engage more with phatic posts than with health misinformation on Facebook." Palgrave Communications 6(1):1-9.

Binderkrantz, Anne. 2008. "Different groups, different strategies: How interest groups pursue their political ambitions.” Scandinavian Political Studies 31(2):173-200.

Bortree, Denise Sevick and Trent Seltzer. 2009. "Dialogic strategies and outcomes: An analysis of environmental advocacy groups' Facebook profiles." Public relations review 35(3):317-319.

Chalmers, Adam William and Paul Alexander Shotton. 2016. "Changing the face of advocacy? Explaining interest organizations' use of social media strategies.” Political Communication 33(3):374-391.

De Bruycker, Iskander and Jan Beyers. 2019. "Lobbying strategies and success: Inside and outside lobbying in European Union legislative politics.” European Political Science Review 11(1):5774.

Dür, Andreas and Gemma Mateo. 2013. “Gaining access or going public? Interest group strategies in five European countries.” European Journal of Political Research 52(5):660-686.

Figenschou, Tine Ustad and Nanna Alida Fredheim. 2020. "Interest groups on social media: Four forms of networked advocacy." Journal of Public Affairs 20(2):1-8.

Gainous, Jason and Kevin Wagner. 2014. Tweeting to Power: The Social Media Revolution in American Politics. Oxford University Press.

Golbeck, Jennifer, Justin Grimes and Anthony Rogers. 2010. "Twitter use by the US Congress." Journal of the American Society for Information Science and Technology 61(8):1612-1621.

Grossman, Shelby, Daniel Bush and Renée DiResta. 2019. Evidence of Russia-Linked Influence Operations in Africa. White paper. Stanford Internet Observatory. 
Grossmann, Matt. 2012. The Not-So-Special Interests: Interest Groups, Public Representation, and American Governance. Stanford University Press.

Hanegraaff, Marcel and Arlo Poletti. 2019. "Public opinion and interest groups' concerns for organizational survival." European Political Science Review: EPSR 11(2):125-143.

Heiss, Raffael, Desiree Schmuck and Jörg Matthes. 2019. "What drives interaction in political actors' Facebook posts? Profile and content predictors of user engagement and political actors' reactions." Information, Communication \& Society 22(10):1497-1513.

Johnson, Dennis. 2011. Campaigning in the twenty-first century: A whole new ballgame? Routledge.

Junk, Wiebke Marie. 2016. "Two logics of NGO advocacy: understanding inside and outside lobbying on EU environmental policies.” Journal of European Public Policy 23(2):236-254.

Kollman, Ken. 1998. Outside Lobbying: Public Opinion and Interest Group Strategies. Princeton University Press.

Larsson, Anders Olof. 2019. "Right-wingers on the Rise Online: Insights from the 2018 Swedish Elections." New Media \& Society p. 1461444819887700.

Lovejoy, Kristen, Richard D Waters and Gregory D Saxton. 2012. "Engaging stakeholders through Twitter: How nonprofit organizations are getting more out of 140 characters or less." Public relations review 38(2):313-318.

Nownes, Anthony J and Patricia Freeman. 1998. "Interest Group Activity in the States." The Journal of Politics 60(1):86-112.

Obar, Jonathan A, Paul Zube and Clifford Lampe. 2012. "Advocacy 2.0: An analysis of how advocacy groups in the United States perceive and use social media as tools for facilitating civic engagement and collective action." Journal of information policy 2:1-25.

Rackaway, Chapman. 2014. Communicating Politics Online. Palgrave Macmillan. 
Schattschneider, Elmer E. 1975. "The Semi-Sovereign People: A Realist's View of Democracy in America.”.

Schlozman, Kay Lehman and John T Tierney. 1986. Organized Interests and American Democracy. Harper and Row.

Sørensen, Mads. 2016. "Political conversations on Facebook - the participation of politicians and citizens." Media, culture \& society 38(5):664-685.

Tumasjan, Andranik, Timm Sprenger, Philipp Sandner and Isabell Welpe. 2011. "Election forecasts with Twitter: How 140 characters reflect the political landscape." Social science computer review 29(4):402-418.

Van der Graaf, Amber, Simon Otjes and Anne Rasmussen. 2016. "Weapon of the Weak? The Social Media Landscape of Interest Groups.” European Journal of Communication 31(2):120_ 135.

Walker, Jack L. 1991. Mobilizing Interest Groups in America: Patrons, Professions, and Social Movements. University of Michigan Press. 